\title{
Control of marine bacteria and diatom biofouling by constant and alternating potentials
}

\author{
Jana Schwarzea, Wolfgang Schuhmann ${ }^{b}$, Axel Rosenhahn ${ }^{a^{*}}$ \\ aAnalytical Chemistry - Faculty of Chemistry and Biochemistry, Biointerfaces, Ruhr \\ University Bochum, Universitätsstraße 150, D-44780 Bochum \\ ${ }^{b}$ Analytical Chemistry - Center for Electroanalytical Sciences (CES), Faculty of \\ Chemistry and Biochemistry, Ruhr University Bochum, Universitätsstraße 150, D- \\ 44780 Bochum
}

*corresponding author: axel.rosenhahn@rub.de

The attachment of the marine bacterium C. marina and the marine diatom N. perminuta on gold coated glass electrodes in the presence of constant potentials of $-0.3 \mathrm{~V}, 0.3 \mathrm{~V},-0.8 \mathrm{~V}, 0.6 \mathrm{~V}$, and alternating potentials (APs) of $-0.3 \mathrm{~V} / 0 \mathrm{~V} / 0.3 \mathrm{~V}$ as well as of $-0.8 \mathrm{~V} / 0 \mathrm{~V} / 0.6 \mathrm{~V}$ was shown in the article. For the sake of clarity, we only showed the averaged data of three independent experiments in the manuscript. To demonstrate the quality and the reproducibility of the experiments, the following Figures show the three independent experiments with C. marina (Figure S1) and $N$. perminuta (Figure S2) at $-0.3 \mathrm{~V}, 0.3 \mathrm{~V}$, and in the presence of APs of $0.3 \mathrm{~V} / 0 \mathrm{~V} / 0.3 \mathrm{~V}$ (Figures S1A and S2A) as well as at $-0.8 \mathrm{~V}, 0.6 \mathrm{~V}$, and in the presence of APs of $-0.8 \mathrm{~V} / 0 \mathrm{~V} / 0.6 \mathrm{~V}$ (Figures S1B and S2B). 

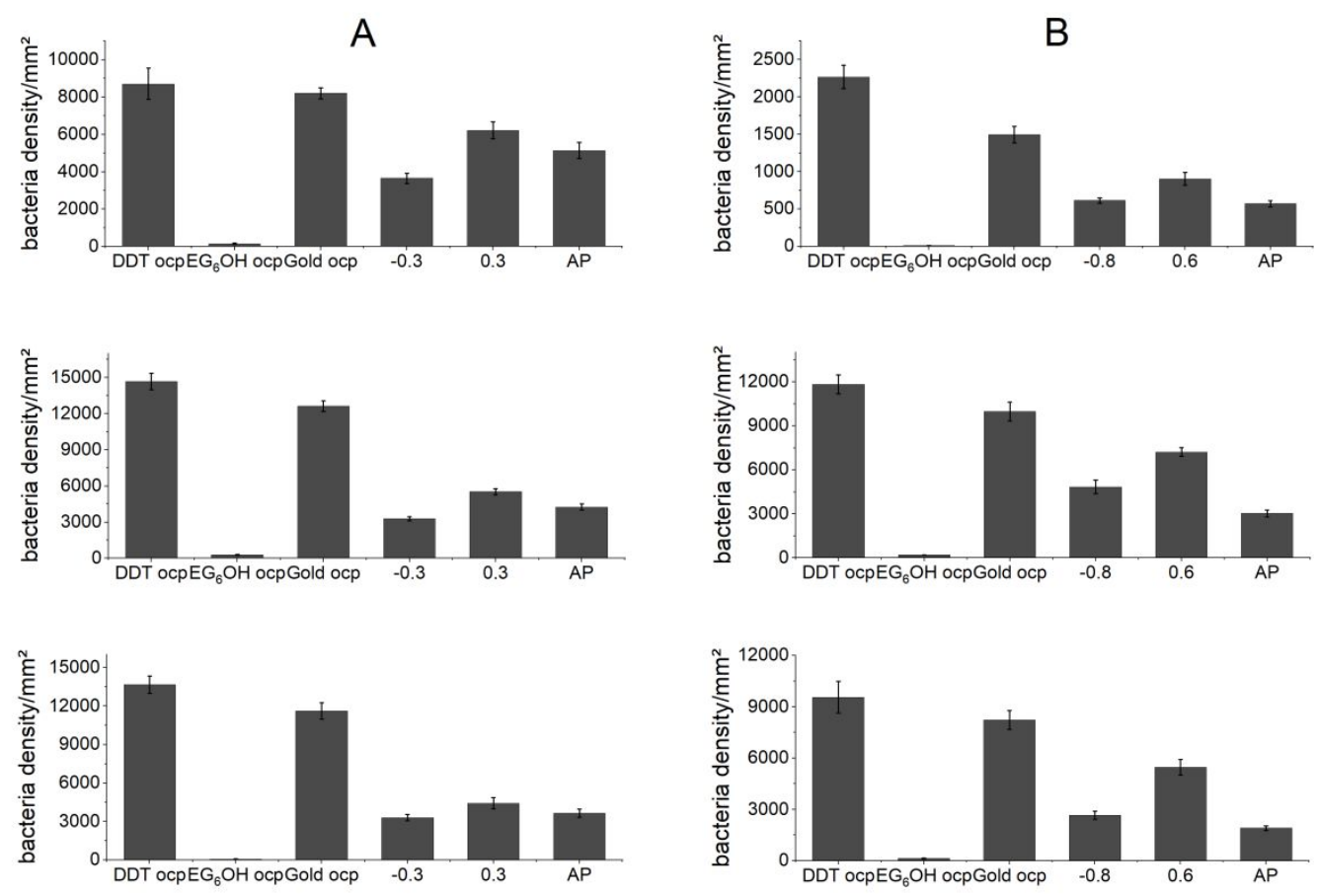

Figure S1: Attachment of the marine bacterium C. marina at $-0.3 \mathrm{~V}, 0.3 \mathrm{~V}$, and in the presence of APs of $-0.3 \mathrm{~V} / 0 \mathrm{~V} / 0.3 \mathrm{~V}(\mathrm{~A})$, and to surfaces with different applied potentials of $-0.8 \mathrm{~V} / 0.6 \mathrm{~V}$, and APs of $0.8 \mathrm{~V} / 0 \mathrm{~V} / 0.6 \mathrm{~V}$ (B). For the APs, the single potentials were hold for $2 \mathrm{~s}$. Three single and independent experiments are shown for each potential and APs applied. The duration of the entire assay was $2 \mathrm{~h}$. The error bars represent the standard error. To test the statistical significance, an analysis of variance (ANOVA) with post hoc Tukey test at a significance level of $\alpha=0.05$ was applied. 

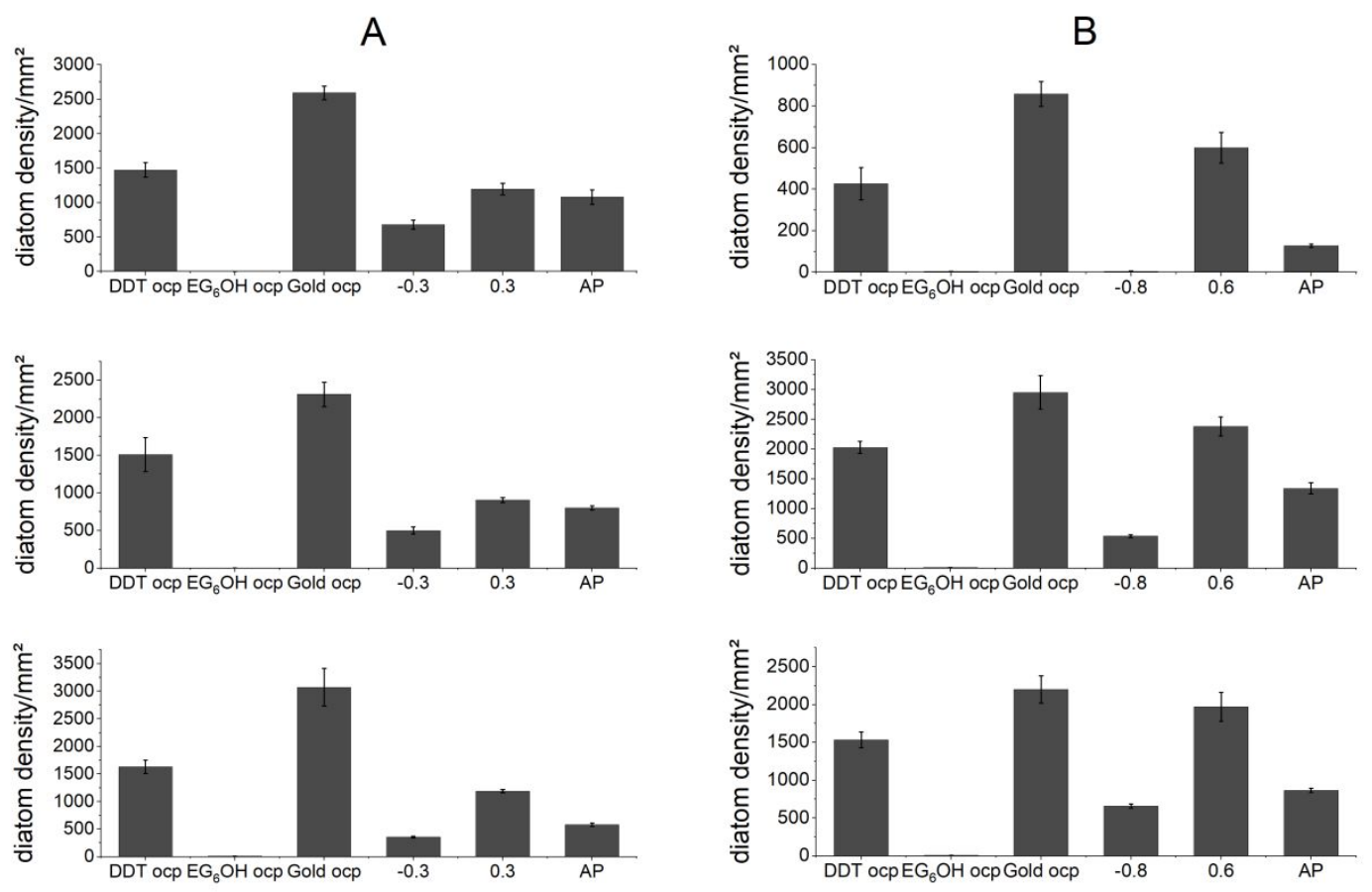

Figure S2: Attachment of the marine diatom $N$. perminuta at $-0.3 \mathrm{~V}, 0.3 \mathrm{~V}$, and in the presence of APs of $-0.3 \mathrm{~V} / 0 \mathrm{~V} / 0.3 \mathrm{~V}(\mathrm{~A})$, and to surfaces with different applied potentials of $-0.8 \mathrm{~V} / 0.6 \mathrm{~V}$, and APs of $0.8 \mathrm{~V} / 0 \mathrm{~V} / 0.6 \mathrm{~V}$ (B). For the APs, the single potentials were hold for $2 \mathrm{~s}$. Three single and independent experiments are shown for each potential and APs applied. The duration of the entire assay was $2 \mathrm{~h}$. The error bars represent the standard error. To test the statistical significance, an analysis of variance (ANOVA) with post hoc Tukey test at a significance level of $\alpha=0.05$ was applied. 